\title{
Sinais detectados entre 0 biológico e 0 maquínico
}

Artur Cabral é artista computacional e mestrando bolsista CAPES pela Universidade de Brasília. Atualmente faz parte da equipe do Medialab/UNB, onde em suas pesquisas explora a relação de vida não natural (a-life) em diálogo com vidas naturais por meio de interfaces e poéticas computacionais.

<arturcabralreis@gmail.com >

ORCID: 0000-0002-4190-3965

Suzete Venturelli é professora e artista_designer computacional da Universidade Anhembi Morumbi (PPGDesign) e Universidade de Brasília (PPGAV). Pesquisadora do CNPq. Coordena o MediaLab/UAM. Participa de congressos e exposições nacionais e internacionais. <suzeteventurelli@gmail.com >

ORCID: 0000-0003-0254-9286

Gilbertto Prado é artista e coordenador do Grupo Poéticas Digitais. Tem realizado e participado de inúmeras exposições no Brasil e no exterior. Atualmente é Professor dos Programas de Pós-Graduação em Design da Universidade Anhembi Morumbi e do PPG Artes Visuais da ECA - USP. <gttoprado@gmail.com > ORCID: 0000-0003-2252-3489
Resumo 0 texto discute a possibilidade de simbiose, ou seja, interação entre espécies como os sistemas biológicos e os maquínicos, que pode ocorrer nas propostas que envolvem pesquisas em arte, design e tecnologia. Nesse viés, sugere-se que a condição computacional induz a uma maneira de se experimentar o mundo que é indeterminado e fragmentário, propondo um tipo de colapso das fronteiras tradicionais entre arte, design e natureza; entre artificial e natural.

Palavras chave Arte computacional, Design computacional, Tecnologia, Emergência.

\section{Signals detected between biological and machinic}

Abstract The goal of the text is discussing the possibility of symbiosis, interaction between species such as biological systems and machines, which may occur in proposals involving research in art, design and technology. In this bias, it is suggested that the computational condition induces a way of experiencing the world that is undetermined and fragmentary, proposing a kind of collapse of the traditional boundaries between art, design and nature; between artificial and natural.

Keywords Computer art, Computer design, Technology, Emergency. 


\section{Introdução}

Fig 1. Amoreiras, Exposição Emoção Art.ficial 5.0. Itaú Cultural São Paulo

Algumas experimentações artísticas em conjunto com o design e tecnologia são propostas que visam estabelecer aproximações entre seres vivos, o ambiente e os objetos que nos envolvem. Nesse sentido, as obras a seguir descritas, levantam questões sobre a linha difusa que separa o que se entende por natural e o artificial, apresentando como argumento que a linha divisória entre "natural" e "artificial" é muitas vezes bastante obscura, pois há uma enorme área encoberta nessa dicotomia. A existência de uma área nebulosa não invalida o conceito de "natural" versus "artificial", mas pode tornar a distinção menos dramática, por meio das poéticas a seguir apresentadas.

A obra Amoreiras de Gilberto Prado e Grupo Poéticas Digitais ${ }^{1}$, é composta por cinco árvores plantadas em vasos e foi instalada na Avenida Paulista em São Paulo. As amoreiras foram equipadas com próteses motorizadas e sistema de detecção de variações e discrepâncias de ruídos, os quais sintoma dos diversos poluentes e poluidores. Nesse sistema, as árvores balançavam por meio de "próteses motorizadas" e algoritmo de aprendizado artificial de acordo com variação dos fatores de poluição. A obra coloca em diálogo as árvores, as máquinas e o ambiente que integra seu sistema. (PRADO, 2018).

Fonte: Gilbertto Prado, 2010

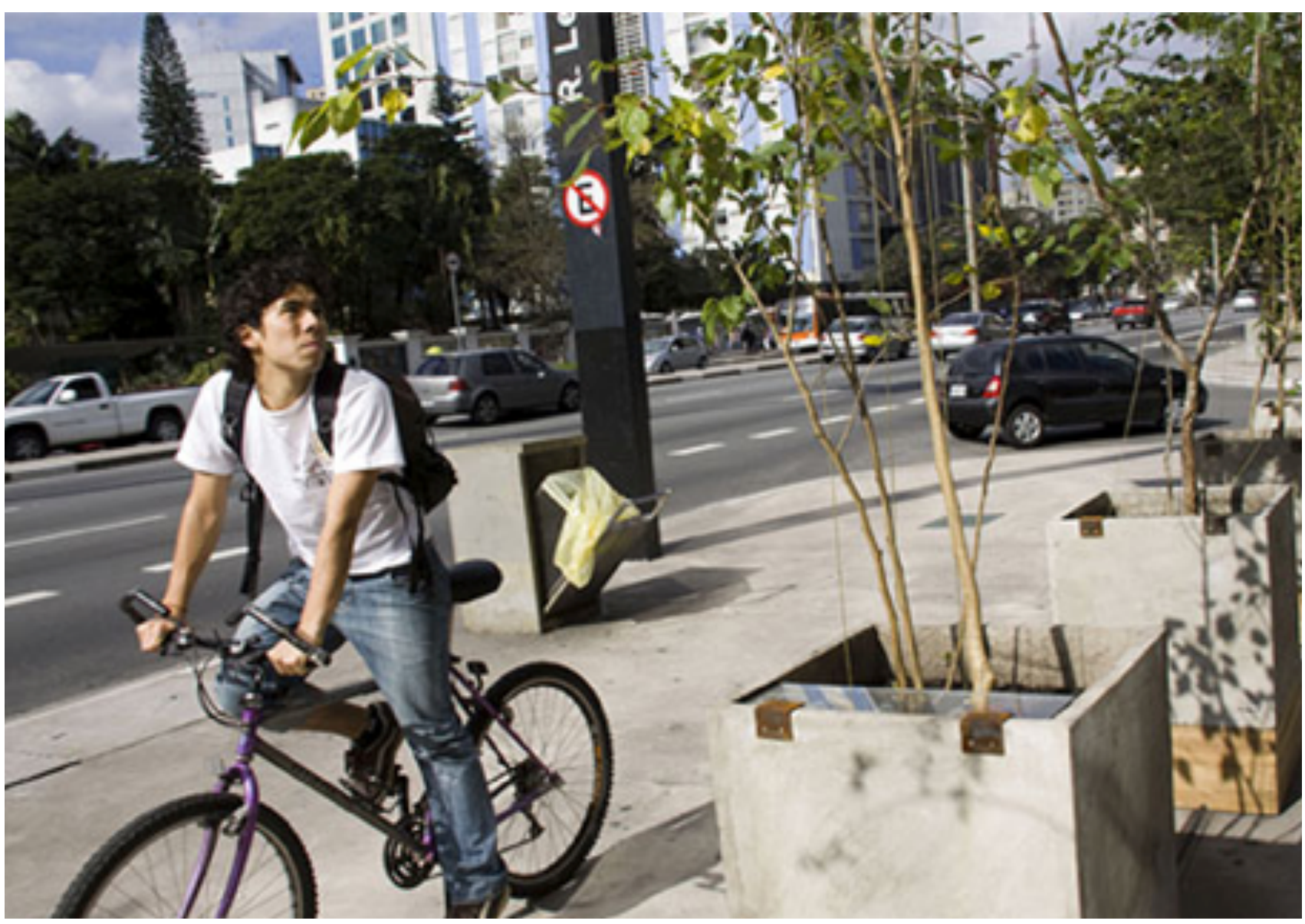


Nesse viés, a obra Cyberflor elaborada no Laboratório de pesquisa em arte computacional da Universidade de Brasília (Medialab/UnB) ${ }^{2}$, é composta por orquídea que controla uma impressora tridimensional, ou seja, simbolicamente uma planta coordena a natureza artificial - sua tecnologia. Nessa obra, um software desenvolvido em equipe, converte os sinais de resistência galvânica, que variam de acordo com as condições climáticas do ambiente e com os processos eletroquímicos da planta, entendidos aqui como sinais vitais da orquídea. A impressora por sua vez, imprime em tempo real formas generativas a partir de algoritmos genéticos. Neste projeto, ocorre a possibilidade de gerar formas em mutação, que metaforicamente aproxima a ideia de vida artificial da ideia de vida natural, trazendo as formas generativas e emergentes como resultado para a impressão 3D.

Incorporada no objeto, uma tela transmite os sinais da planta por intermédio de uma interface singular de visualização de dados. Mediante a interface o espectador percebe que ocorre uma correlação entre a planta e as impressões. A relação sensorial entre a orquídea é fundamental no contexto poético, pois busca-se que se estabeleça um diálogo entre planta e máquina. A forma impressa, como resultado desse diálogo, considera a primitiva geométrica cubo como morfogênese do projeto, que ao ser subdividida por parâmetros aleatórios, gera um padrão complexo, ao se repetir dentro da forma. A repetição do padrão faz surgir uma forma conhecida como fractal. A modelagem da forma final é dada a partir da lógica de auto-semelhança. Para Mandelbrot (2016), os fractais são representações gráficas do caos e a lógica de auto-semelhança remete às formas da natureza.

\section{A poética emergente}

Fig 2. Cyberflor, exposição Museu Nacional da República, Brasília Fonte: Suzete Venturelli, 2018
Desse modo, consideramos neste trabalho que a origem de sua forma, é o seu DNA, que surge de algoritmos estruturados a partir do conceito de arte e vida artificial, significando que não ocorrerá jamais duas impressões iguais. Depois de concebida artificialmente, a vida artificial, estabelece contato com o ambiente natural recebendo sinais provenientes da orquídea, os quais vão provocar a sua mutação e nova adaptação da sua morfogênese. Estimulando sua capacidade de se auto-organizar. A poética emergente, nesse caso, é procedural, que se manifesta na programabilidade e autonomia dos sistemas computacionais.

A tecnologia computacional dá um sentido diferente ao conceito de criação artística que leva à arte, ao design à tecnologia emergente. Esse conceito envolve a compreensão de que o processo da criação não é linear, pois ocorre interações imprevisíveis entre os sistemas.

Outro exemplo, no qual o conceito de emergência é percebido, é o trabalho intitulado de F-Orchis, que possui grande complexidade poética e técnica, e propõe dar continuidade aos estudos decorrentes da obra Cyberflor. 


\section{Projeto Amoreiras}

A instalação interativa Amoreiras é composta basicamente de:

- 5 Amoreiras de grande porte e 5 grandes vasos de cimento;

- 3 Microfones, que captarão os ruídos e funcionarão como sensores e coletores dos dados para as árvores;

- 1 Computador que gerencia os dados das 5 árvores e retransmite as informações;

- 5 Placas arduino bluetooth (uma para cada árvore);

- 5 Caixas de acrílico com 3 motores independentes, varetas e mecanismo de transmissão (uma para cada árvore).
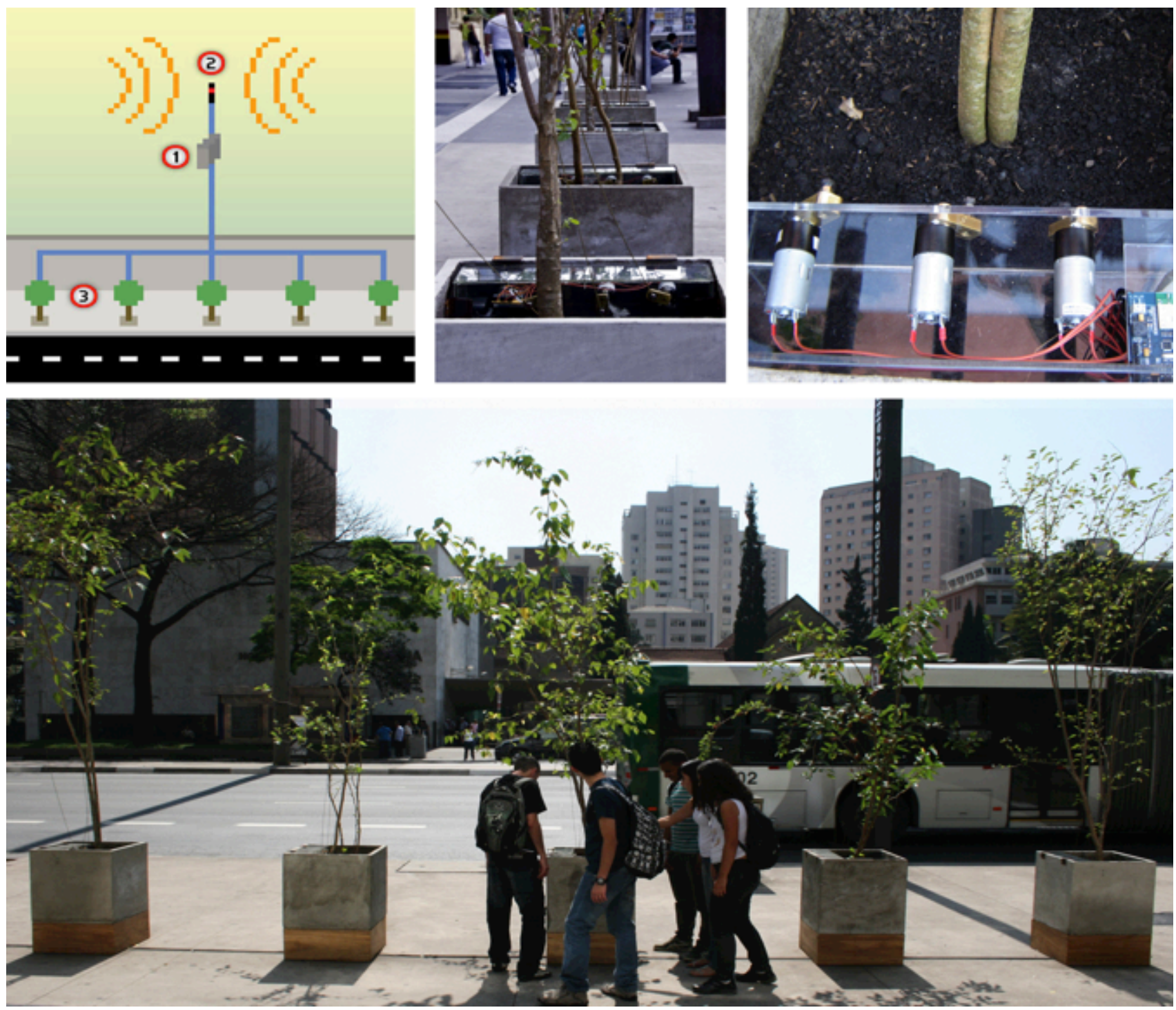

Fig 5. Amoreiras, Exposição Emoção Art.ficial 5.0. Itaú Cultural São Paulo, 2010.

Fonte: Gilbertto Prado 2017 
O comportamento de cada árvore é autônomo e acontece em resposta à intensidade do som ambiente, também sendo influenciada pela "personalidade" de cada árvore. A captura de som será realizada diretamente por um patch escrito no Pure Data, que enviará as informações para a aplicação principal, desenvolvida em Java, via OSC. Já a "personalidade" de cada árvore é definida por duas variáveis, sorteadas no início de cada dia, que definem o quanto cada árvore irá buscar imitar as suas companheiras (ignorando os estímulos sonoras) e o quanto o seu comportamento será perturbado de forma aleatória.

Ao longo do dia, as "aprendizes", inicialmente desajeitadas, pouco a pouco passam a reagir cada vez mais autonomamente em relação aos dados recebidos de poluição, balançando-se quando houver muito ruído (que será uma baliza para o reconhecimento do nível de poluição) e descansando quando a ameaça for menor. Até o final da tarde, já se nota diferença em seus comportamentos, mostrando que elas estão aprendendo e talvez também dialogando entre si, intercambiando dados numa dança de próteses maquínicas, e combinadas com o balançar do vento em suas folhas.

Cada árvore tem um algoritmo que determina como ativar os seus motores (via Arduíno) de acordo com a atividade sonora. De uma maneira geral, quanto maior o ruído, maior atividade (é importante ressaltar que há regras adicionais, como por exemplo, intensidade e extensão da vibração, para que os movimentos sejam suaves; limite de duração de tempo, período em que se pode balançar a árvore, de forma a não danificá-la).

As árvores podem "ver" o comportamento das outras árvores, de modo que cada uma é influenciada pelo comportamento das árvores vizinhas. Esta capacidade é utilizada pelo algoritmo do trabalho para avaliar o comportamento de cada árvore - por comportamento nos referimos ao nível de ativação dos motores. Quanto mais parecido for o comportamento de uma árvore com o comportamento das demais, melhor avaliado será o comportamento.

Inicialmente o algoritmo é "não habituado", o que leva a comportamentos "sem sentido" (por exemplo: as árvores balançam mesmo sem ruído). Um algoritmo de aprendizado monitora o banco de dados e observa constantemente o comportamento de cada árvore, compara com a atividade sonora e tenta adaptar o Algoritmo para agir de maneira similar. Isto é, o algoritmo de aprendizado tenta fazer com que o Algoritmo de cada árvore chegue ao mesmo nível de ativação que os das demais para uma dada intensidade sonora.

Para realização do algoritmo das Amoreiras estamos nos orientando pelos princípios do jogo da vida de John Conway.(GARDNER, 1970) O que fazemos, é aplicar princípios de vizinhança ao processo de auto-avaliação das amoreiras. Isto é, o comportamento das duas (ou apenas uma, se a amoreira estiver em uma das extremidades) amoreiras adjacentes possuem um peso maior do que o das amoreiras mais distantes. Isto poderia facilitar a ocorrência de comportamentos com possíveis combinações de acionamento dos motores. 
O trabalho foi apresentado na mostra Emoção Art.ficial 5.0, Itaú Cultural, São Paulo de junho a setembro de 2010 e na III Mostra 3M de Arte Digital: Tecnofagias, Instituto Tomie Ohtake, São Paulo de agosto a setembro de 2012 com a curadoria de Giselle Beiguelman.

\section{Flores de plástico não morrem}

A instalação interativa intitulada Flores de Plástico Não Morrem ${ }^{3}$ é constituída, de filamentos plásticos e sistemas luminosos. A partir do encontro das tecnologias de objetos conectados e da Internet das Coisas, criamos uma selva de plástico, com plantas e flores interconectadas que formam um biótopo computacional com características do cerrado. Biótopo, é um conjunto de condições físicas e químicas que caracterizam um ecossistema ou bioma. Nesse bioma, pétalas generativas, flores de plástico, disseminação de luz formam uma atmosfera especial desse ecossistema.

Nessa proposta cada flor é constituída de hastes formadas por cano de policloreto de vinil (PVC) reaproveitados, no qual variam de altura a cada produção. As pétalas, sépalas e pedúnculo partem de uma morfogênese digital e generativa. Para o desenvolvimento de cada flor são coletados dados mediante sensores (resistência galvânica) acoplados a plantas, as quais cultivamos no laboratório de novas mídias da Universidade de Brasília. Como sua morfogenia é definida pelas informações contidas nessa espécie de DNA, a cada geração essa vida artificial apresenta-se visualmente com mudanças sutis de uma forma para outra, não contendo duas iguais. $O$ resultado desse processo recebe adaptações em um software de modelagem 3D, para que possa ser impresso e receber os componentes eletrônicos e circuitos da peça.

Fig 6. Impressões das flores de plástico geradas a partir dos sinais de resistência galvânica das plantas. Fonte: Artur Cabral Reis, 2019
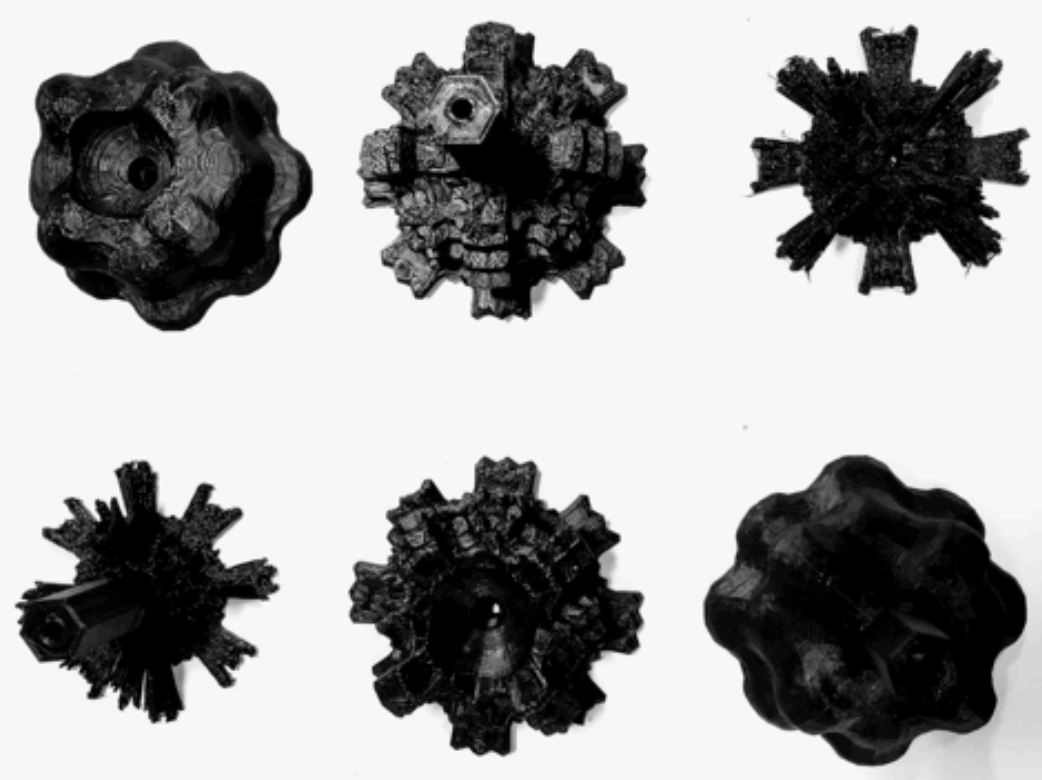
Depois de impressas, em cada flor é acoplado uma espécie de estigma iluminado, que varia sua intensidade luminosa e sua cor de acordo com a interação com as outras flores. Essa interação se dá a partir de um jogo interativo de autômatos celulares, um clássico algoritmo que simule processos complexos que se assemelham à vida natural. Nesse caso, cada estigma das flores é constituído por uma cúpula de plástico na qual envolve uma tríade de células luminosas, um conjunto de leds RGB. Essas células habitam em um ecossistema, por meio da comunicação endógena e exógena de cada elemento com sua vizinhança. Por instrumento de um conjunto de regras, os mesmos podem mudar seu estado de vivo (aceso) para morto (apagado) e vice-versa, a cada geração .

Como mencionado, o desenvolvimento de sistemas de autômatos celulares não é algo recente, é comumente atribuído a Stanisław Ulam e John von Neumann, ambos pesquisadores no Laboratório Nacional de Los Alamos, no Novo México, na década de 1940 . Von Neumann por sua vez, tinha um interesse especial em auto-organização e evolução, prevendo um mundo de robôs auto-replicantes e autônomos em um certo nível (SHIFFMAN, 2012).

Em 2002, Stephen Wolfram inaugura uma nova fase para os estudos em autômatos celulares, motivado pelas pesquisas de Neumann, escreveu o livro "A New Kind of Science", onde destaca a relevância destas simulações para a pesquisa científica nas áreas da biologia, química, física e todos os ramos da ciência moderna. Nesse livro, Wolfram, elabora a ideia autômatos celulares elementares, autômatos semelhantes ao Jogo da vida (Game of live), como declarado, formulado pelo matemático John Horton Conway em 1970, um autômato celular que simula alterações em populações de seres vivos unicelulares baseados em regras locais e simples onde cada célula vive ou morre de acordo com sua vizinhança. A grande diferença dos autômatos de Conway para os autômatos elementares de Wolfram é a sua simplicidade e fácil implementação, uma vez que o Jogo da Vida necessita de uma matriz bidimensional para sua execução, o jogo dos autômatos elementares pode funcionar em uma simples grade unidimensional.

Ainda que mais simples, os autómatos celulares elementares mediante seu jogo de interação por vizinhança, proporcionam propriedades características de sistemas complexos. Aplicando um conjunto de regras para calcular o estado de cada geração de células a partir da condição de seus vizinhos, temos a emergência de padrões complexos e fractais. Como exemplo, se aplicarmos o conjunto de regras conhecidas como "Regras 90" propostas por Wolfram ao sistema de autômatos celulares, podemos perceber a emergência de um padrão complexo conhecido como triângulo de Sierpiński, mesmo padrão que pode ser observado no mundo natural, como constatámos na concha do molusco gastrópode Conus textile (SHIFFMAN, 2012).

Tomando como inspiração os autômatos celulares elementares de Wolfram, concebemos o processo de comunicação das flores nessa instalação. Como citado anteriormente, cada estigma destas flores de plástico é formado por uma tríade celular, um trio de leds onde juntos compõem o sistema RGB, 
com base na "Regra 90" em cada led incorporado no estigma da flor, verifica-se o estado atual da sua vizinhança interna, ou seja, o led posicionado a direita e à esquerda, e em seguida altera-se seu estado para viva (acesa) ou morta (apagada) a cada partida executada nesse sistema interativo.

Além da comunicação interna das células luminosas (leds) esse sistema comporta uma comunicação exógena entre os estigmas das flores, onde plantas computacionais interagem umas com as outras por meio de uma rede formada componentes eletrônicos, denominada também de Internet das Coisas (IoT).

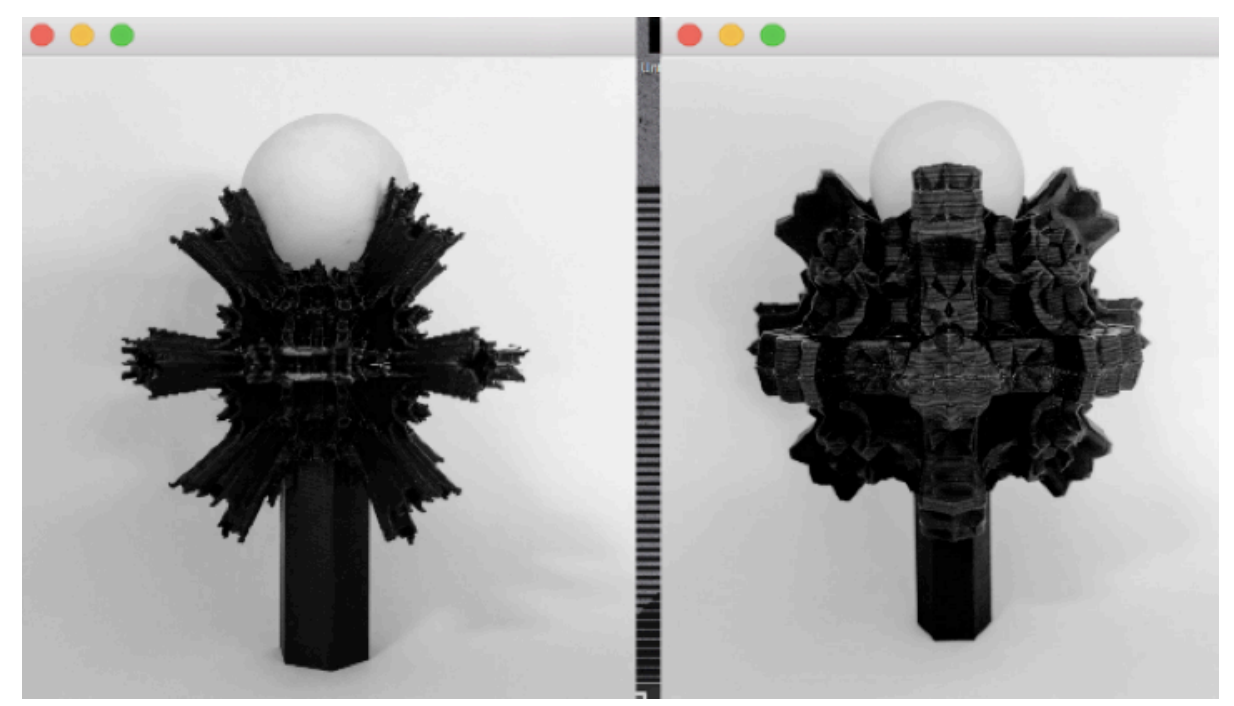

Fig 7. Protótipos da flor de plástico Fonte: Artur Cabral Reis, 2019

A cada interação muda-se o estado de todos os leds, a partir da sua vizinha interna e externa conectada através de uma rede. Nesse sistema, um microcontrolador Arduino é usado para promover essa espécie de intranet das plantas de plásticos, assim como para controlar e processar os algoritmos quais coordenam os estados dos leds com base nas regras estabelecidas para este jogo.

Como resultado temos a formação de um bioma computacional, uma selva de plástico e componentes eletrônicos, na qual um conjunto de interações complexas fomentam o surgimento de comportamentos emergentes, dando origem a um sistema autogerativo e objetos interativos os quais estabelecem relações cibernéticas entre máquina-máquina atuando em um ecossistema com atmosfera e espaço-tempo singular.

Este jogo complexo e orgânico dirigido por regras simples, em sua dimensão poética questiona como a biotecnologia está impactando bio-esfera. Assim como, anseia revelar as mudanças de civilização que estamos experimentando, bem como sua mudança climática, em função do meio ambiente degradado. A mensagem principal apresenta que a apropriação de tecnologias por cada um é uma ação, que nos permite agir sobre questões urgentes e não somente permanecer como um simples consumidor. 
MAGALHÃES, Ana Gonçalves; BEIGUELMAN, Giselle (Org.). Futuros Possíveis: Arte, Museus e Arquivos Digitais. São Paulo: Ed. Peirópolis, 2014.

MANDELBROT, Benôit. The fractal geometry of nature. Disponível em: <https://ordinatous.com/pdf/The_Fractal_Geometry_of_Nature.pdf>. Acesso em: 29 de nov. 2018.

PRADO, Gilbertto; La Ferla, Jorge (Ed.). Circuito Alameda. Ciudad de México: Instituto Nacional de Bellas Artes | Laboratorio Arte Alameda, 2018. http://www.gilberttoprado.net/assets/circuito_alameda_gttoprado_jlf.pdf

PRADO, Gilbertto. Project Amoreiras (Mulberry Trees): Autonomy and Artificial Learning in an Urban Environment. Leonardo 2018 51:1, 61-62. The MIT Press https://doi. org/10.1162/LEON_a_01557

PRADO, Gilbertto. Grupo Poéticas Digitais: Dialogo y Medio Ambiente. ANIAV - Revista de Investigación en Artes Visuales, [S.1.], v. 1, n. 1, p. 47-58, jul. 2017. Disponible en: <https:// polipapers.upv.es/index.php/aniav/article/view/7820>. Acesso em 15 jul. 2017 doi:https:// doi.org/10.4995/aniav.2017.7820.

PRADO, Gilbertto. Grupo Poéticas Digitais: projetos desluz e amoreiras. ARS (São Paulo), São Paulo, v. 8, n. 16, 2010 . pp. 110-125. Disponível em <http://www.scielo.br/scielo. php?script=sci_arttext\&pid=S1678-53202010000200008\&lng=pt\&nrm=iso>. Acesso em 05 jun. 2011. doi: https://doi.org/10.1590/S1678-53202010000200008

SHIFFMAN, Daniel. The Nature of Code: Simulating Natural Systems with Processing. New York: The Nature of Code, 2012.

VENTURELLI, Suzete. Arte Computational. Brasília: Edunb, 2017.

VENTURELLI Suzete; ROCHA Cleomar; SILVA, Teófilo Augusto da; COUTINHO, Cláudio; REIS, Artur Cabral Reis; MARTINS, Tainá e HARGREAVES, Prahlada. Poiesis do corpo. IN: DATJournal v. 3 n. 1 (2018): DOI: https://doi.org/10.29147/dat.v3i1.78

SOGABE, Milton; PERES, Carolina; FOGLIANO, Fernando; NUNES, Fabio Oliveira; BRAZ, Soraya; PERES, Carolina; GAZANA, Cleber Gazana: Sopro. IN: DATJournal v. 2 n. 1 (2017) DOI: https://doi.org/10.29147/2526-1789.DAT.2017v2i1p104-114 